\title{
An Intelligent Control System of Remanufacturing Assembly for Improving Quality and Production Efficiency
}

\section{Conghu Liu}

Shanghai Jiao Tong University

Wei Cai ( $\nabla$ weicai@swu.edu.cn )

Southwest University https://orcid.org/0000-0003-0412-9197

Guang Zhu

Suzhou University

Mengdi Gao

Suzhou University

Original Article

Keywords: Remanufacturing, Assembly, Intelligent control, Production efficiency, Resource efficiency, Quality

Posted Date: May 20th, 2021

DOI: https://doi.org/10.21203/rs.3.rs-531440/v1

License: (9) (1) This work is licensed under a Creative Commons Attribution 4.0 International License. Read Full License 


\section{Title page}

\section{An intelligent control system of remanufacturing assembly for improving quality and production efficiency}

Conghu Liu, born in 1981, is currently a visiting scholar of Tsinghua University, Beijing, China, a postdoctoral of Shanghai Jiao Tong University, Shanghai, China and an associate professor of Suzhou University, Suzhou, China. His research interests include green manufacturing and intelligent control.

E-mail: 1ch339@126.com

Wei Cai, born in 1991, is currently is a postdoctoral fellow of The Hong Kong Polytechnic University, Hong Kong, China and a lecturer of Southwest University, Chongqing, China. His research interests include green manufacturing, sustainability assessment and responsible production.

E-mail: weicai@swu.edu.cn

Guang Zhu, born in 1978, is currently a professor at Suzhou University, Suzhou, China. His research interests include green manufacturing and preparation of photosensitive materials.

E-mail: guangzhu@ahszu.edu.cn

Mengdi Gao, born in 1991, received his doctorate from Hefei University of technology in 2017, and is currently an associate professor of Suzhou University, Suzhou, China.

E-mail: mengdgao@163.com

\section{Corresponding author: Wei Cai E-mail: weicai@swu.edu.cn}




\title{
ORIGINAL ARTICLE
}

\section{An intelligent control system of remanufacturing assembly for improving quality and production efficiency}

\author{
Conghu Liu ${ }^{1,4}$ • Wei Cai ${ }^{2,3}$ • Guang Zhu' ${ }^{1}$ Mengdi Gao ${ }^{1}$
}

Received June xx, 201x; revised February xx, 201x; accepted March xx, 201x

(C) Chinese Mechanical Engineering Society and Springer-Verlag Berlin Heidelberg 2017

\begin{abstract}
'Abstract: Remanufacturing has been considered to be one of the most effective ways to deal with sustainable manufacturing. The integration of intelligent technology and remanufacturing assembly system is a necessary way for the development of remanufacturing industry. This paper proposes an intelligent control system for improving the quality and production efficiency of the remanufacturing assembly (reassembly) systems. First, the state space model of reassembly is constructed and deduced to reveal the quality transfer and coupling mechanism of reassembly process. An optimization model of the reassembly scheme is established for minimizing the comprehensive cost. Then, an intelligent control system for reassembly process is proposed, which is a real-time monitoring and dynamic compensation response to address abnormal quality and to achieve intelligent control of reassembly process. The data model, information perception and fusion technology, real-time monitoring and dynamic compensation of reassembly quality are studied and implemented. Finally, the prototype intelligent control system of reassembly is developed, which illustrates its practicability offering a technical support for sustainability of remanufacturing. It can monitor the abnormal quality in real time and make dynamic compensation response, and realize the intelligent control of reassembly process. It plays a positive role in improving quality, reducing cost and enhancing customer satisfaction. This intelligent control method is more suitable for the reassembly system of complex machinery, especially under uncertain operating environment.
\end{abstract}

Wei Cai

weicai@swu.edu.cn

1 Sino-US Global Logistics Institute, Shanghai Jiao Tong University, Shanghai, 200030, China

2 Department of Logistics and Maritime Studies, Faculty of Business, The Hong Kong Polytechnic University, Hung Hum, Kowloon, Hong Kong, China

3 College of Engineering and Technology, Southwest University, Chongqing, 400715, China

3 School of Mechanical and Electronic Engineering, Suzhou University, Suzhou, 234000, China
Keywords: Remanufacturing - Assembly; Intelligent control • Production efficiency • Resource efficiency; Quality

\section{Introduction}

With the rapid development of the economy and the society, the contradiction between economic growth and resource consumption in the world has become increasingly serious [1]. The remanufacturing technology with low carbon and energy saving has been recognized as a viable way to protect the global ecological environment and solve the shortage of resources [2]. It is an effective way to create a resource-saving and environment-friendly society, and highly in line with sustainable development [3]. Compared with the original products, the remanufactured products can save energy by $60 \%$, materials by $70 \%$ and cost by $50 \%$, almost no solid waste is produced, and the emission of air pollutants is reduced by more than $80 \%$ [4]. However, remanufactured products with low carbon and environmental protection are difficult to meet customer expectations [5] and market demand [6]. The quality of remanufactured products becomes the shackle of the development of the remanufacturing industry [7].

How to balance the uncertainty of remanufactured parts with high quality and resource efficiency becomes a challenge for the remanufacturing assembly system [8]. In order to reduce the quality error caused by the uncertainty of remanufactured parts, many experts and scholars pay research efforts on remanufacturing process management in recent years. The relevant literature is as following. On the optimization model of reassembly production, a graph-based optimization model for simultaneous reassembly and procurement planning in assemble-to-order remanufacturing systems is studied by $\mathrm{Oh}$ and Behdad [9]. Considering inventory and reassembly capability, a recover-and-assemble remanufacturing system to optimize smoothing and the safety stocks is proposed by Zahraei [10]. And a methodology for a systematic, concurrent consideration of design for reassembly and disassembly guidelines and constraints for product 
remanufacturing is proposed by Soh [11]. Then, a mathematical model and solution algorithms to determine the disassembly, reprocessing and reassembly lot-sizes is studied Cho [12]. Moreover, an optimization method is presented byJiang [13] for remanufacturing process planning for improving reliability and reducing cost in remanufacturing systems. The scheduling algorithm for job-shop-type remanufacturing systems with parts matching requirement is studied by $\mathrm{Yu}$ and Lee [14]. These studies mainly focus on minimizing costs and maximizing benefits to construct optimization models and methods for reassembly systems in uncertain operating environments.

As for the management direction of remanufacturing system, the value of regulating returns for enhancing the dynamic behaviour of hybrid manufacturing-remanufacturing systems is studied by Ponte [15]. The impact of human resources on remanufacturing process, internal complexity, perceived quality of core, numerosity, and key process indicators is explored by Arredondo-Soto [16]. An integrated optimization control method for reassembly system is built by Liu [17]. And a joint production and maintenance problem is addressed by Ndhaief under environmental constraints and reliability issues in a manufacturing/remanufacturing context [18]. Similarly, environmental benefits and costs assessment model for remanufacturing process under quality uncertainty is studied by Liao [19]. Furthermore, lean remanufacturing is used as a tool to improve the performance of reassembly system by Vasanthakumar [20, 21], and to tackle remanufacturing process challenges and achieve shorter lead times [22].

The reassembly system, which is excellent quality, high efficiency, energy conservation, materials saving and environmental protection, is key to ensure that remanufactured products meet diversification, personalization, and green aspect of the customer's need. However, comparing with the original manufacturing assembly system, reassembly system is characterized with higher operating uncertainty [23], complexity, and dynamics. There are many phenomena, such as low production efficiency [24], unstable product quality, frequent abnormal production accidents, and high product repair rate, which make the optimization and control of reassembly system a challenge to be solved for remanufacturing production management [25].

As mentioned above, it is a challenge for managing reassembly system to deal with uncertain information, enhance the utilization of remanufactured parts, ensure the stability of reassembly process, and improve the quality of remanufactured products. The above studies made an important contribution to improve the management and control ability of reassembly system, but the extant research mainly focuses on quality control, operation optimization, planning and scheduling, and has achieved a lot of meaningful results. However, these targets mainly at the level of models and methods, which need to be studied and integrated into an intelligent management and control platform to provide greater impetus for optimal management of reassembly system.

To overcome the above-mentioned problem, an intelligent control system of reassembly is proposed to increase the utilization ratio of remanufactured parts and improve reassembly quality with the uncertain environment, dynamic process, and complex task requirements. It provides theoretical and methodological support for optimizing the configuration of reassembly resources and improving the production efficiency.

To achieve above research goals, the paper has been organized as follows: Section 2 explains the framework, model and, key technologies of intelligent control information system. Section 3 verifies the validity and feasibility of the intelligent control system for a remanufacturing engine assembly workshop.

\section{Intelligent control system of remanufacturing assembly}

It appears that the intelligent control system of reassembly is key to guarantee the quality and production efficiency of reassembly system, which determines performance reliability and customer satisfaction [26]. Therefore, it is important to study the intelligent control system in order to realize the high production and resource efficiency towards achieving sustainable development of remanufacturing industry. In order to achieve the above goals, this section studies (i) Framework, (ii) Modelling, and (iii) Key development technologies of intelligent control system.

\subsection{Framework}

The intelligent control system of reassembly consists of four layers: data perception layer, network layer, model operation layer, and intelligent control layer. These four layers are integrated with existing manufacturing execution system (MES) technology and applied in reassembly system.

\section{- Data perception layer}

Based on the recognition, classification and identification of reassembly resources, the data perception layer collects reassembly resources (materials, equipment, personnel, energy, and environment) and their status data in the reassembly process. For attribute information of remanufactured parts and the different grades of reassembly operations, special identification and two-dimensional code are used. The reassembly perception layer can online recognize and dynamic perceive the information and operation status of reassembly resources.

\section{- Network layer}

It is mainly composed of fieldbus, sensor network, Ethernet, Internet, network management system, and data management system. It can transform, store, route, and transfer protocol for multi-source sensing data. 
- Model operation layer

With the help of data perception layer and network layer, the idea of object-oriented design is used to map the physical perception data of reassembly shop to its resource state and behavior. Then, the state space model of reassembly calculates and deduces the data to represent the operation state of the reassembly system and predict the quality. Combined with the quantity and quality level of remanufacturing parts, reused parts and original parts, as well as the operation ability of the remanufacturing process, the reassemble scheme optimization model is deduced to rationally allocate resources in the reassembly workshop.

\section{- Intelligent control layer}

The reassembly intelligent control layer mainly monitors, analyses, extracts, and optimizes the perceptual fusion information to realize the intelligent control for reassembly system. Its functions are visual monitoring, real-time tracking, optimal decision-making, on-line quality control, scheme formulation and quality information traceability. It makes the real-time monitor and quality dynamic compensation in the assembly process and realizes remanufacturing intelligent assembly to ensure the reassembly quality and the service security of remanufactured products. The intelligent control system also provides services such as resource configuration, data security, protocol conversion and system application [28].

The intelligent control system of reassembly is a hardware and software integration system (Fig 1), so how to integrate these technologies in a platform is a difficult problem to design and implement. Our solution is as following: The integrated development environment is JAVA. The heterogeneity of reassembly resources are configured and developed by SIMATIC STEP and WINCC. Oracle is used as the Web server database to realize the development of the system and function modules. Industrial middleware (such as KepserverEX) is applied to map the physical address of hardware resources in the configuration system to the address of resource middleware. The reassembly process is used as a carrier to configure production processes, reassembly stations (such as intelligent management and control resources, data addresses and production events), and production rules (such as coding rules, dimensional chain and quality standards). The optimization model of the reassembly scheme, real-time monitoring and dynamic compensation is encapsulated in jar file format, which is convenient for the system call and transplantation.

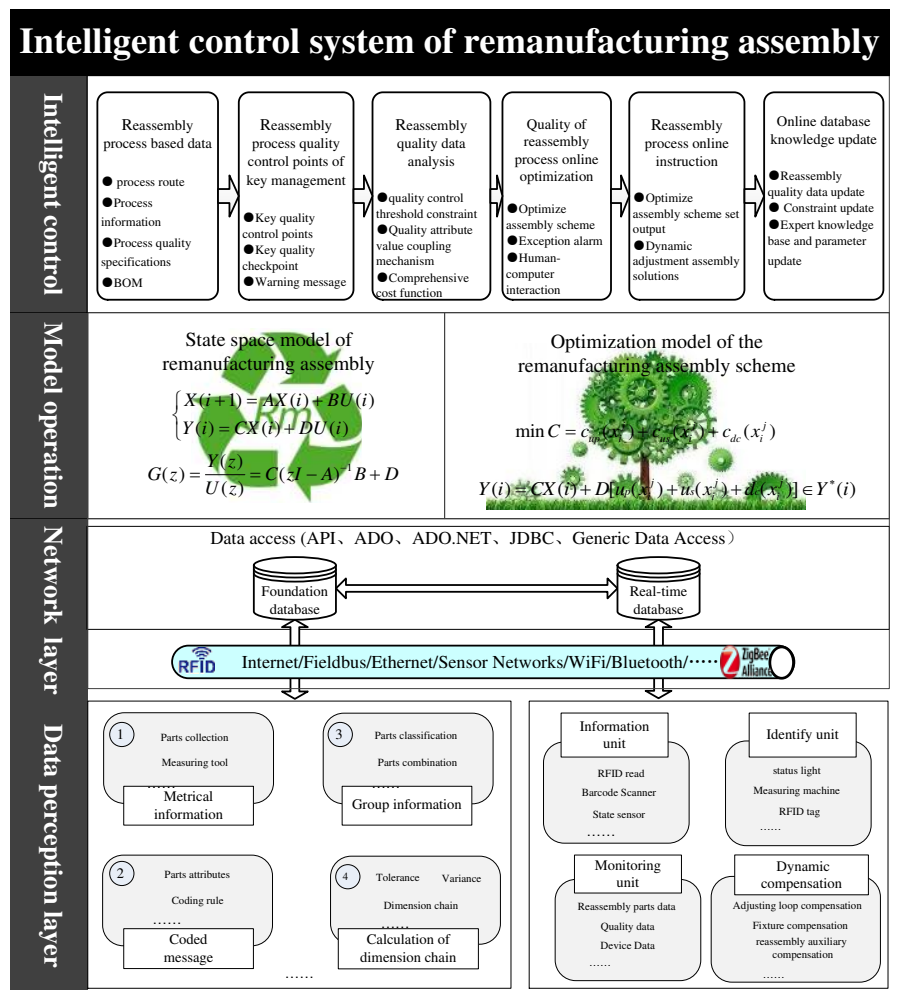

Figure 1 The framework of the intelligent control system

\subsection{Modelling}

Because each process is independent in time, multi process remanufacturing assembly process can be regarded as discrete event process. In order to describe the model accurately, this paper defines it as follows:

- The remanufactured product is composed of various types of remanufactured parts, reused parts and new parts. It is assembled in a specific assembly station according to a certain assembly sequence, and conforms to a number of quality and technical standards

- A reassembly station only assembles one part. If a station assembles multiple parts, it is decomposed into multiple stations.

- The quality attribute value of reassembly is obtained through online real-time information acquisition technology. Each reassembly station has its own quality standard. If the reassembly quality does not meet the standard, there are corresponding quality compensation measures.

Reassembly is a multi-input and multi-output process. In view of the fact that the reassembly process is dominated by the reassembly station, and has the dual characteristics of time sequence and space sequence, this study intends to characterize the coupling mechanism of reassembly quality through state space modeling. The state space model of reassembly is as follows.

$$
\left\{\begin{array}{l}
X_{i+1}=\alpha X_{i}+\beta U_{i} \\
Q_{i}=\chi X_{i}+\delta U_{i}
\end{array}\right.
$$

Where, $i$ is $i$-th reassembly station. $X_{i}$ is the state vector 
of the reassembly station (WIP state). $U_{i}$ is the input vector of $i$-th reassembly station. $Q_{i}$ is the output vector of reassembly quality. According to the actual production data, the matrix $\alpha, \beta, \chi, \delta$ can be determined.

Based on the above state space model, the reassembly quality transfer function is determined. The state space model of reassembly quality transfer is a discrete multiple input multiple output system. The basic method is the Z-transform reassembly quality transfer function.

$$
\left\{\begin{array}{c}
z X_{z}-z x_{0}=\alpha X_{z}+\beta U_{z} \\
Q_{z}=\chi X_{z}+\delta U_{z}
\end{array}\right.
$$

Where, $\mathrm{z}$ is a variable. Its main role is a variable used in the derivation of the formula.

From formula (2) we can deduce that

$$
\left\{\begin{array}{c}
X_{z}=(z I-\alpha)^{-1} \beta U_{z}+z(z I-\alpha)^{-1} x_{0} \\
Q_{z}=\chi X_{z}+\delta U_{z}
\end{array}\right.
$$

Further derivation shows that:

$$
\begin{aligned}
& Y_{z}=\chi(z I-\alpha)^{-1} \beta U_{z}+z \chi(z I-\alpha)^{-1} x_{0}+\delta U_{z} \\
& =\left[\chi(z I-\alpha)^{-1} \beta+\delta\right] U_{z}+z \chi(z I-\alpha)^{-1} x_{0}
\end{aligned}
$$

It is known that the initial value of the reassembly, $x_{0}=0$, so:

$$
Q_{z}=\left[\chi(z I-\alpha)^{-1} \beta+\delta\right] U_{z}
$$

The transfer function matrix of reassembly quality is defined as:

$$
G_{z}=\frac{Q_{z}}{U_{z}}=\chi(z I-\alpha)^{-1} \beta+\delta
$$

The reassembly quality transfer function matrix (formula 6) can quantitatively describe the relationship between the input vector of each reassembly station and the reassembly quality. The mechanism of reassembly error transfer, accumulation and coupling is revealed. It provides accurate quantitative support for the quality prediction and control of reassembly process.

In the reassembly system, the cost of different parts (remanufacturing parts, original parts) is different, and the cost of different assembly operations of corresponding parts is also different. In order to realize the comprehensive optimization of production efficiency and quality of reassembly, we define:

$$
U_{i}=u_{p}\left(x_{i}^{j}\right)+u_{s}\left(x_{i}^{j}\right)
$$

$u_{p}\left(x_{i}^{j}\right)$ is the input vector of part $x_{i}^{j}$ in $i$-th reassembly station.

$u_{s}\left(x_{i}^{j}\right)$ is the operation input vector for part $x_{i}^{j}$ in $i$-th reassembly station.

Remanufacturing production requires that the output vector of each station must meet the reassembly quality standard.

$$
Q_{i} \in Q_{i}^{*}
$$

$Q_{i}^{*}$ is reassembly quality standard.

There is no doubt that due to the uncertainty of remanufacturing parts and reassembly system, through the prediction of reassembly state space model, some reassembly quality may not meet the standard.

$$
Q_{i} \notin Q_{i}^{*}
$$

Therefore, dynamic compensation measures (such as adjusting ring compensation) should be added to ensure that:

$$
Q_{i}=\chi X_{i}+\delta\left[u_{p}\left(x_{i}^{j}\right)+u_{s}\left(x_{i}^{j}\right)+d_{c}\left(x_{i}^{j}\right)\right] \in Q^{*}{ }_{i}
$$

In the process of remanufacturing production, remanufacturing parts, reassembly operation and dynamic compensation measures all need production cost. Therefore, in order to minimize the comprehensive cost of reassembly, this paper constructs the optimization model of assembly scheme.

$$
\min C=c_{u p}\left(x_{i}^{j}\right)+c_{u s}\left(x_{i}^{j}\right)+c_{d c}\left(x_{i}^{j}\right)
$$

Where, $c_{u p}\left(x_{i}^{j}\right)$ is cost of part $x_{i}^{j} . c_{u s}\left(x_{i}^{j}\right)$ is cost of reassembly operation for part $x_{i}^{j} . c_{d c}\left(x_{i}^{j}\right)$ is cost of dynamic compensation measures for part $x_{i}^{j}$. Of course, the optimal solution can be obtained by dynamic programming and genetic algorithm, which will not be discussed here.

\subsection{Key development technologies}

Based on the framework of the intelligent control system and reassemble scheme optimization model, an intelligent control information system is needed to implement this function. Therefore, the following key technologies are necessary for designing and developing the information system.

\subsubsection{Data model}

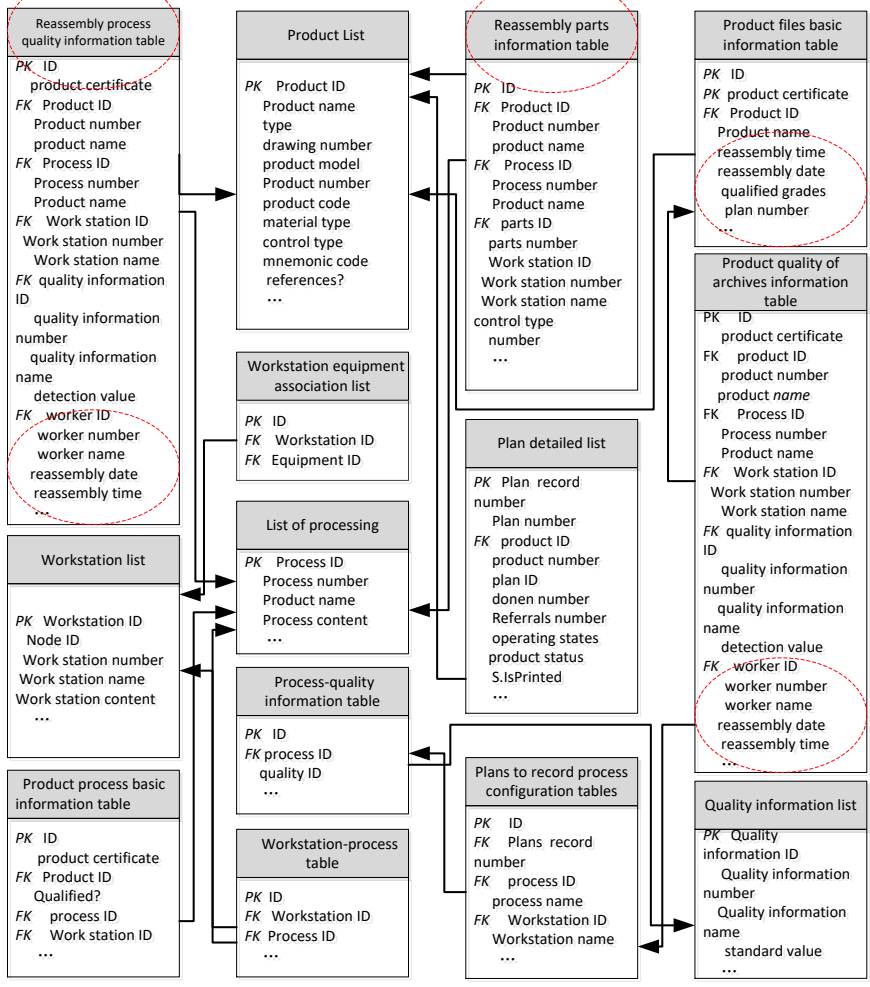

Figure 2 Data model

The database is the basis for intelligent control system of 
the reassembly process, so it is the key factor of intelligent level and running properly of the system. Data model design directly affects the efficiency and ease of system maintenance, and it is also related to the stability and robustness. The following figure shows the system's data model, and we list the main system database tables and the corresponding mappings of the intelligent control system of reassembly process.

The data model inherits the framework and structure of original manufacturing, but also makes necessary modification and supplement according to the remanufactured parts and reassembly process (Fig 2). This provides a basis for the realization of intelligent control system of reassembly.

\subsubsection{Information perception and fusion technology}

The paper implements the measurement, grouping, coding and calculation by information perception and fusion technology, whose main contents are as follows (Fig 3):

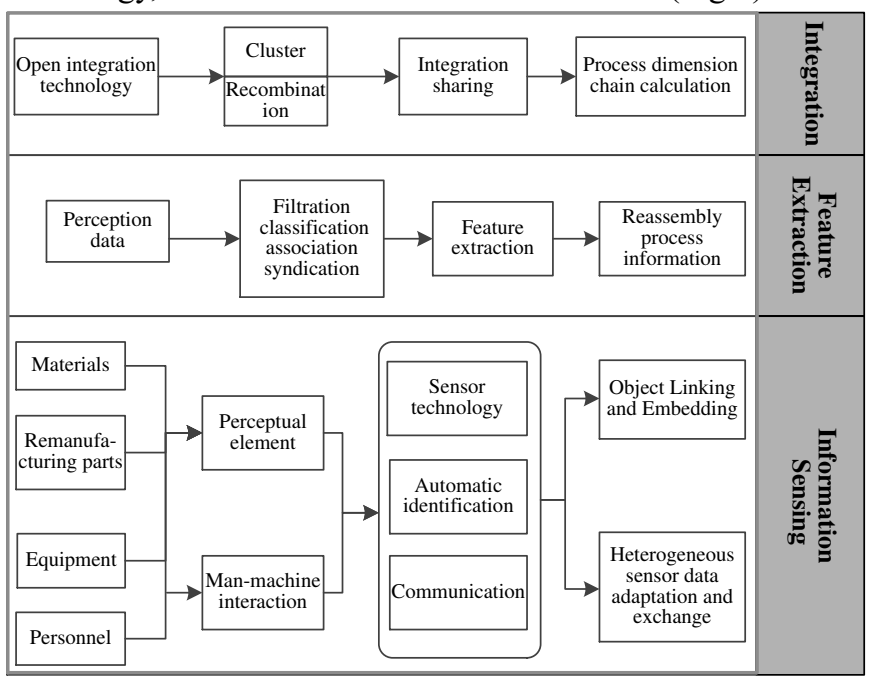

Figure 3 Information perception and fusion technology

Information sensing: Equipment, people, materials and other reassembly resources are equipped with corresponding sensing elements. Internet, communication, computer, automatic identification and sensing technology are used comprehensively. Open and interoperable interface standard and object linking and embedding technology are defined to solve the problem of heterogeneous sensing data adaptation and exchange. It actively perceives reassembly resource and its process state data, and realizes the mapping between physical perception data and reassembly resource state and behavior.

Feature extraction: It can filter, group, association and aggregate the perception data of reassembly system to form real-time and dynamic information of the reassembly process, so as to realize accurate extraction of remanufacturing resource state and representation of process state.

Information integration: The object-oriented open integration technology is adopted, and all the information in the reassembly system is standardized and coded. On this basis, according to the needs of information use, the information and its functional structure and association relationship are clustered and reorganized, and then the information with unified data form is generated, and finally the information integration and sharing of the whole system are realized.

\subsubsection{Real-time monitoring and dynamic compensation of reassembly quality}

Due to the high uncertainty of the remanufacturing process, abnormal events occur frequently in the reassembly process. The intelligent control system must be combined with the real-time situation of the production site, so as to solve all kinds of sudden problems timely and accurately. Accurate and reliable information of remanufacturing parts and real-time quality data are the premise of successful operation of reassembly intelligent control system. Firstly, the quality data of WIP are identified, and then the quality attribute values of key quality control points are collected. On the basis of information collection and processing, based on the real-time assembly information of reassembly workshop, the real-time monitoring and dynamic compensation of reassembly quality are realized.

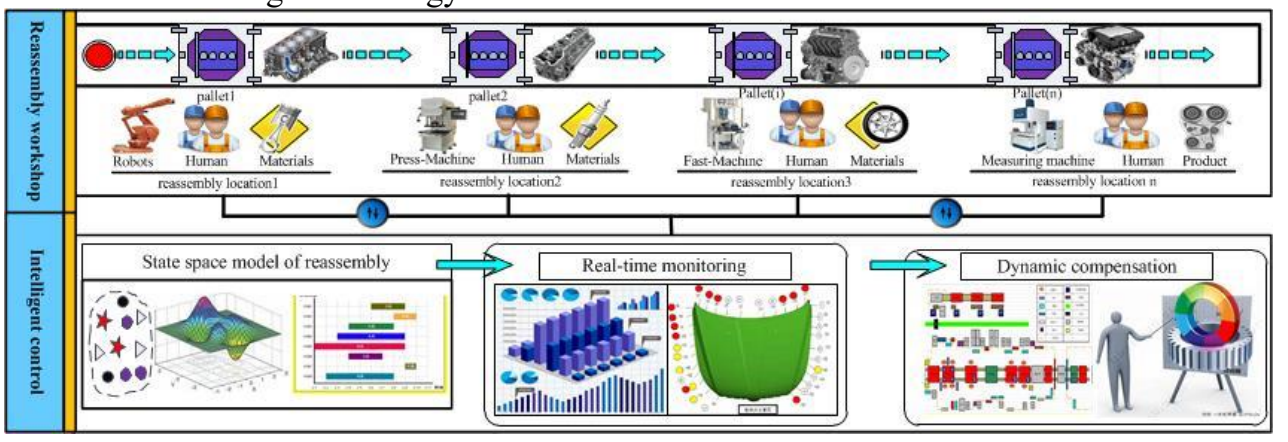

Figure 4 Real-time monitoring and dynamic compensation of reassembly quality 
Based on data perception layer and network layer, the real-time perception and collection of reassembly process data are realized. The information of remanufactured parts, the state and behavior of reassembly resources is dynamically mapped in real time. Then, the state space model of reassembly is integrated, the reassembly process is monitored online, and the real-time quality monitoring is achieved. According to the operational information of remanufacturing parts and reassembly station, based on the comparison of simulation and reality of the reassembly process, the dynamic data of the reassembly process are monitored, analyzed and mined, and the quality of key quality points of reassembly is predicted. When the quality is abnormal, the corresponding intelligent control strategy is formulated to dynamically compensate the reassembly process. Intelligent control is realized in reassembly workshop (Fig 4).

\section{Case study}

This case illustrates the data-driven remanufacturing assembly intelligent control system in a remanufacturing enterprise, also analyzes the significance and value. The case study has four aspects: (1) background, (2) system analysis, (3) application effect, and (4) discussion and management enlightenment.

\subsection{Background}

A remanufactured engine company dismantled the recycled waste engine, cleaned, and tested the worn parts and reused parts, and remanufactured the worn parts by the remanufacturing technical transformation. Then, the reused parts and remanufactured parts are assembly in the reassembly workshop. After field investigation, the project team found the following problems in the company's remanufactured engine assembly workshop. There are many uncertain factors in the reassembly process, the tolerance zone of the quality attribute value of remanufactured parts and reused parts is large, the range of reassembly quality error fluctuates greatly, the control standard of reassembly quality refers to the original manufacturing standard, and the utilization rate of remanufactured parts is low. In view of these difficulties and challenges, the prototype intelligent control system for remanufactured engine assembly process is designed and developed in the virtual reassembly workshop of our research group.

\subsection{System analysis}

Based on J2EE framework, Oracle is used as Web server database. The prototype intelligent control system for remanufactured engine reassembly process has been developed with the associated enabling technology. In view of the actual situation of the reassembly workshop of engine remanufacturing, the information collection and fusion system adopts RFID, IC reader, PDA and scanning gun to integrate in human-machine interface. It provides real-time and dynamic data support for intelligent control information system of reassembly process.

Information collection can collect the information of remanufactured parts, including the collection of key quality inspection items, data analysis, upper and lower limits of quality data (Fig 5-I). The inventory information of remanufactured parts can also be integrated and queried by the system in time, including the type, quantity and quality level of remanufactured parts (Fig 5-II). The key quality information of remanufactured parts also can be retrieved, including coating thickness and other important remanufacturing details (Fig 5-III). Remanufacturing parts information, reassembly process data, and related operations are integrated in the background to provide support for intelligent control (Fig 5-IV).

Based on the state space model of reassembly and reassembly quality error transfer derivation, the intelligent control system can predict the reassembly quality (Fig 6-I); at the same time, the reassembly process is monitored in real time, and the reassembly quality information is displayed accurately online (Fig 6-II). According to the information of remanufactured parts, the optimal feasible assembly scheme is derived. The system identifies the scheme and outputs the optimized reassembly scheme (Fig 6-III). The system can dynamically monitor the quality control chart and dynamically compensate the abnormal quality in real time (Fig 6-IV). Intelligent control of reassembly process is realized.

The intelligent control system of reassembly builds a system $\log$ to facilitate the storage and query of information related to reassembly process and provides support for reassembly quality traceability. 


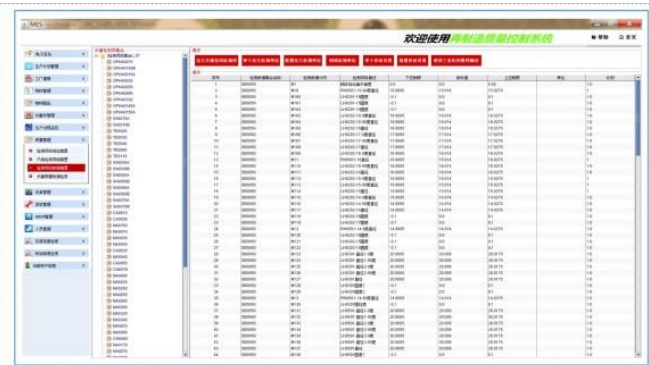

I: Information collection of remanufactured parts

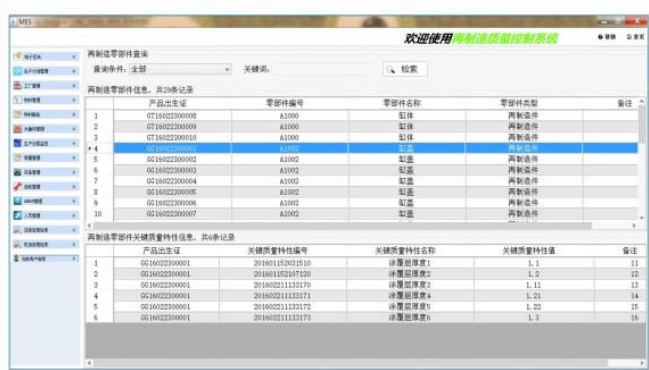

III: Key quality information retrieval of remanufactured parts

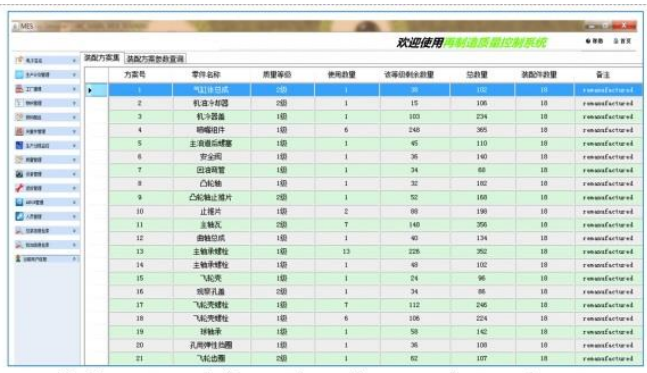

II: Inventory information of remanufactured parts

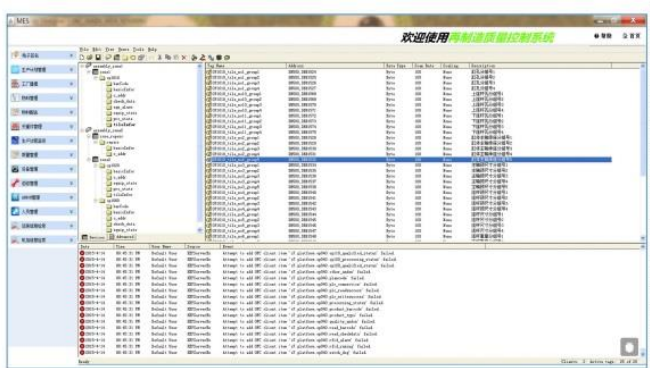

IV: Information data fusion in background

Figure 5 Information collection and fusion module of prototype intelligent control system

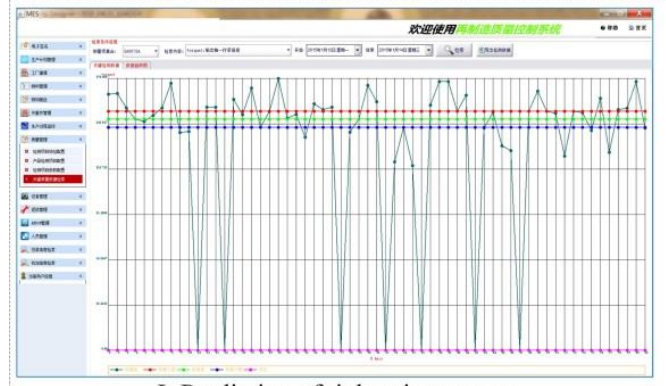

I: Prediction of tightening torque

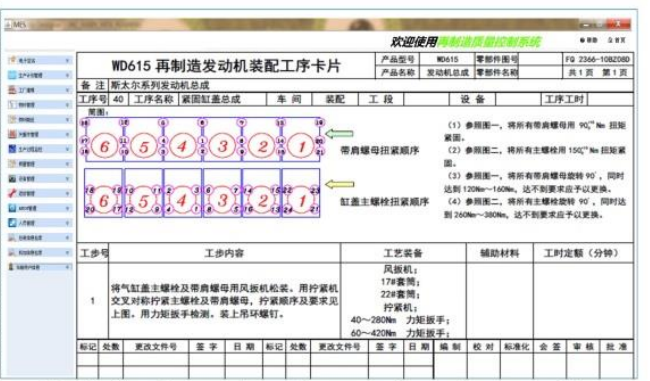

III: Online instruction of remanufacturing assembly

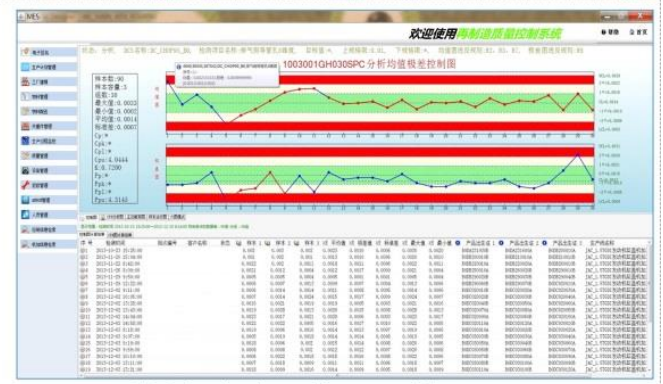

II: Monitoring of reassembly process

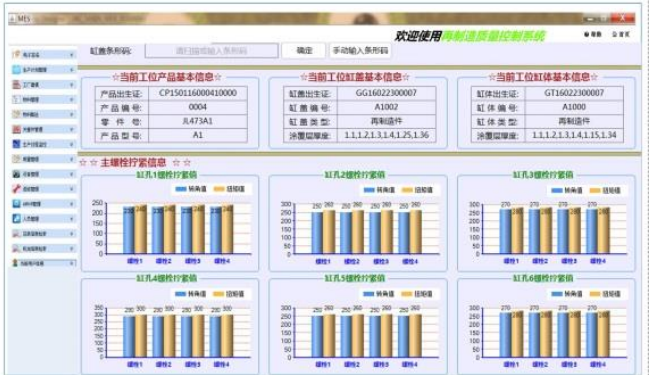

IV: Display of real time data

Figure 6 Monitoring and online guidance of prototype intelligent control system

\subsection{Discussion}

In remanufacturing production inventory management and optimization, the intelligent control system can deduce the optimized reassembly scheme, according to the information of remanufactured parts, reused parts, and original parts in database. It has extended the dimensional accuracy of remanufactured parts, with tolerance reduced by $20 \%$ and variance reduced by $40 \%$.

In remanufacturing production process control and quality management, the intelligent control system can track the position of the remanufactured parts on the reassembly line, monitor the operation process, feedback the results of the reassembly station operation in real time, and accurately guide the operation of the workers in the 
reassembly process. For example, in the reassembly station of remanufacturing crankshaft, it improves the axial clearance qualification rate of $14.4 \%$. The intelligent control system increases the passing rate of torque by $3.67 \%$, makes the engine crankshaft run more smoothly, and reduces piston deflection and connecting rod bending in the virtual reassembly workshop.

In remanufacturing workshop stability management, the intelligent control system can realize the monitoring of materials flow, information flow, reassembly process, and alarm the abnormal situation for the managers.

In remanufacturing production management and service, the intelligent control system can trace the quality of remanufactured assembly, and trace the quality reasons of remanufactured engine by date, order number, abnormal quality, and fault type. For the remanufacturing enterprise, the intelligent control system can efficiently utilize the production data and realize intelligent control, so as to improve the production and resource efficiency.

Compared with the similar direction of literatures, in addition to quality control [17] and uncertain optimization [18], this paper also has system integration. The intelligent control system of reassembly is a preliminary exploration of intelligent manufacturing methods and technologies. It is an effective method to deal with the uncertainty of remanufacturing production. Multi-variety, small-batch and individualized for remanufacturing customer requirements [30], uncertain, complex and dynamic reassembly process, as well as multi-objective requirements of excellent quality, high efficiency, energy conservation, material saving and environmental protection, urgently need the organic combination of intelligent manufacturing technology and reassembly system [31]. Therefore, it is important to study remanufacturing intelligent control system for production and resource efficiency of remanufacturing industry.

\section{Conclusions}

Improving the performance and service safety of remanufactured products to meet customer expectations is necessary for the sustainable development of remanufacturing industry, but the uncertainty and complexity of reassembly process has become a constraint to the quality of remanufactured products. In order to deal with this challenge, the intelligent control system of reassembly is studied with combination of remanufacturing technology and intelligent technology. Its main innovations are as follows: (i) The state space model of reassembly is constructed deduced, the quality transfer and coupling mechanism of reassembly process is revealed; (ii) the optimization model of the reassembly scheme is established for minimizing the comprehensive cost; and (iii) data model, information perception and fusion technology, real-time monitoring and dynamic compensation of reassembly quality are researched for the key technologies of the intelligent control system. Moreover, the prototype intelligent control system is developed in the virtual reassembly workshop of remanufacturing engine, which is the exploration and practice of intelligent remanufacturing.

Intelligent remanufacturing is the deep integration of new generation information technology and remanufacturing, which helps the remanufacturing industry move towards intelligence and high-end. Accelerating the development of intelligent remanufacturing can further improve the management level of remanufacturing technology and the quality of industrial development, which is in line with the development direction of remanufacturing industry.

Of course, this paper is limited to intelligent management of remanufacturing engine assembly workshop, which needs further integration of intelligent space and digital twin technology for remanufacturing system in the future. The research results will enrich and develop the basic theory and technology of intelligent remanufacturing, which has important theoretical significance and application value for the sustainable development of the remanufacturing industry.

\section{Declaration}

\section{Funding}

Supported by Key project of the Anhui Natural Science Foundation (No.2008085me150), National Natural Science Foundation of China (No. 71632007), Hong Kong Scholars Program (XJ2019059), Chinese Postdoctoral Science Foundation (No. 2017M611574), and National Social Science Foundation of China (NO.20BGL108).

\section{Availability of data and materials}

The datasets supporting the conclusions of this article are included within the article.

\section{Authors' contributions}

The author' contributions are as follows: Wei Cai was in charge of the whole trial; Conghu Liu wrote the manuscript; Guang Zhu and Mengdi Gao assisted with sampling and laboratory analyses.

\section{Competing interests}

The authors declare no competing financial interests.

\section{Consent for publication}


Not applicable

\section{Ethics approval and consent to participate}

Not applicable

\section{Acknowledgements}

The authors acknowledge the technical support from Shanghai Jiao Tong University and Hefei University of technology. The project is supported by General program of Anhui Natural Science Foundation (No.2008085me150), Key project of the National Natural Science Foundation of China (No. 71632007), Hong Kong Scholars Program (XJ2019059), National Social Science Foundation of China (NO.20BGL108),

\section{References}

[1] Cai W, Liu C, Zhang C, et al. Developing the ecological compensation criterion of industrial solid waste based on emergy for sustainable development. Energy, 2018, 157:940-948.

[2] Xu B, Dong S, Shi P. States and prospects of china characterised quality guarantee technology system for remanufactured parts. Journal of Mechanical Engineering, 2013, 49(20): 84-90. (in Chinese)

[3] Xu B, Shi P, Liu B, et al. Engineering management problems of remanufacturing industry[J]. Zhingguo Biaomian Gongcheng(China Surface Engineering), 2012, 25(6): 107-111. (in Chinese)

[4] $\mathrm{Xu} \mathrm{B}$, Dong S, Zhu S, et al. Prospects and developing of remanufacture forming technology $[\mathrm{J}]$. Jixie Gongcheng Xuebao(Chinese Journal of Mechanical Engineering), 2012, 48(15): 96-105. (in Chinese)

[5] Vafadarnikjoo A, Mishra N, Govindan K, et al. Assessment of consumers' motivations to purchase a remanufactured product by applying Fuzzy Delphi method and single valued neutrosophic sets. Journal of Cleaner Production, 2018(196): 230-244.

[6] Neto J Q, Bloemhof J M, Corbett C J, et al. Market prices of remanufactured, used and new items: Evidence from eBay. International Journal of Production Economics, 2016, 171(3): 371-380.

[7] Li G, Reimann M, Zhang W, et al. When remanufacturing meets product quality improvement: the impact of production cost. European Journal of Operational Research, 2018, 271(3): 913-925.

[8] Liu C, Cai W, Dinolov O, et al. Emergy based sustainability evaluation of remanufacturing machining systems. Energy, 2018: 670-680.

[9] Oh Y, Behdad S. Simultaneous reassembly and procurement planning in assemble-to-order remanufacturing systems. International Journal of Production Economics, 2017(184): 168-178.

[10] Zahraei S M, Teo C. Optimizing a recover-and-assemble remanufacturing system with production smoothing. International Journal of Production Economics, 2018(197): 330-341.

[11] Soh S L, Ong S K, Nee A Y, et al. Design for assembly and disassembly for remanufacturing. Assembly Automation, 2016, 36(1): $12-24$.

[12] Cho Y H, Doh H H, Lee D, et al. Mathematical model and solution algorithms for capacitated dynamic lot-sizing in remanufacturing systems. Industrial Engineering and Management Systems, 2018, 17(1): $1-13$

[13] Jiang Z, Zhou T, Zhang H, et al. Reliability and cost optimization for remanufacturing process planning. Journal of Cleaner Production, 2016(135): 1602-1610

[14] Yu J M, Lee D H. Scheduling algorithms for job-shop-type remanufacturing systems with component matching requirement. Computers \& Industrial Engineering, 2018, 120:266-278.

[15] Ponte B, Naim M M, Syntetos A A, et al. The value of regulating returns for enhancing the dynamic behaviour of hybrid manufacturing-remanufacturing systems. European Journal of Operational Research, 2019, 278(2): 629-645.

[16] Arredondosoto K C, Realyvasquezvargas A, Maldonadomacias A A, et al. Impact of human resources on remanufacturing process, internal complexity, perceived quality of core, numerosity, and key process indicators. Robotics and Computer-integrated Manufacturing, 2019(59): 168-176.

[17] Liu C, Zhu Q, Wei F, et al. An integrated optimization control method for remanufacturing assembly system. Journal of Cleaner Production, 2020, 248: 119261.

[18] Ndhaief N, Nidhal R, Hajji A, et al. Environmental issue in an integrated production and maintenance control of unreliable manufacturing/remanufacturing systems. International Journal of Production Research, 2019: 1-19.

[19] Liao H, Deng Q, Wang Y, et al. An environmental benefits and costs assessment model for remanufacturing process under quality uncertainty. Journal of Cleaner Production, 2018, 178: 45-58.

[20] Vasanthakumar C, Vinodh S, Vishal A W. Application of analytical network process for analysis of product design characteristics of lean remanufacturing system: a case study. Clean Technologies and Environmental Policy, 2017, 19(4): 971-990.

[21] Vasanthakumar C, Vinodh S, Ramesh K. Application of interpretive structural modelling for analysis of factors influencing lean remanufacturing practices. International Journal of Production Research, 2016, 54(24): 7439-7452.

[22] Kurilova-Palisaitiene J, Sundin E, Poksinska B. Remanufacturing challenges and possible lean improvements. Journal of Cleaner Production, 2018, 172: 3225-3236.

[23] Tian G, Ren Y, Feng Y, et al. Modeling and planning for dual-objective selective disassembly using AND/OR graph and discrete artificial bee colony. IEEE Transactions on Industrial Informatics, 2018, 15(4): 2456-2468.bn n

[24] Sitcharangsie S, Ijomah W, Wong T C. Decision makings in key remanufacturing activities to optimise remanufacturing outcomes: a review[J]. Journal of Cleaner Production, 2019, 232. 1465-1481.

[25] Zhu Q, Lai K. Enhancing supply chain operations with extended corporate social responsibility practices by multinational enterprises: Social capital perspective from Chinese suppliers. International Journal of Production Economics, 2019, 213: 1-12.

[26] Binshi X, Dan X, Junyang T and Shiyun. D.Status and Development of Intelligent Remanufacturing in China. CHINA SURFACE ENGINEERING, 2018, 31(5):1-13. (in Chinese)

[27] Goodall P, Sharpe R, West A. A data-driven simulation to support remanufacturing operations. Computers in Industry, 2019, 105: $48-60$.

[28] Liu M, Ma J, Lin L, et al. Intelligent assembly system for mechanical products and key technology based on internet of things. Journal of Intelligent Manufacturing, 2017, 28(2): 271-299.

[29] Saez M, Maturana F P, Barton K, et al. Real-time manufacturing 
machine and system performance monitoring using internet of things[J]. IEEE Transactions on Automation Science and Engineering, 2018, 15(4): 1735-1748.

[30] Abbey J D, Kleber R, Souza G C, et al. Remanufacturing and consumers' risky choices: Behavioral modeling and the role of ambiguity aversion. Journal of Operations Management, 2019, 65(1): 4-21.

[31] Liu C, Zhu Q, Wei F, et al. A review on remanufacturing assembly management and technology. The International Journal of Advanced Manufacturing Technology, 2019, 105(11): 4797-4808.

\section{Biographical notes}

Conghu Liu, born in 1981, is currently a visiting scholar of Tsinghua University, Beijing, China, a postdoctoral of Shanghai Jiao Tong University, Shanghai, China and an associate professor of Suzhou University, Suzhou, China. His research interests include green manufacturing and intelligent control.

E-mail: 1ch339@126.com

Wei Cai, born in 1991, is currently is a postdoctoral fellow of The Hong Kong Polytechnic University, Hong Kong, China and a lecturer of Southwest University, Chongqing, China. His research interests include green manufacturing, sustainability assessment and responsible production.

E-mail: weicai@swu.edu.cn

Guang Zhu, born in 1978, is currently a professor at Suzhou University, Suzhou, China. His research interests include green manufacturing and preparation of photosensitive materials.

E-mail: guangzhu@ahszu.edu.cn

Mengdi Gao, born in 1991, received his doctorate from Hefei University of technology in 2017, and is currently an associate professor of Suzhou University, Suzhou, China.

E-mail: mengdgao@163.com 


\section{Intelligent control system of remanufacturing assembly}
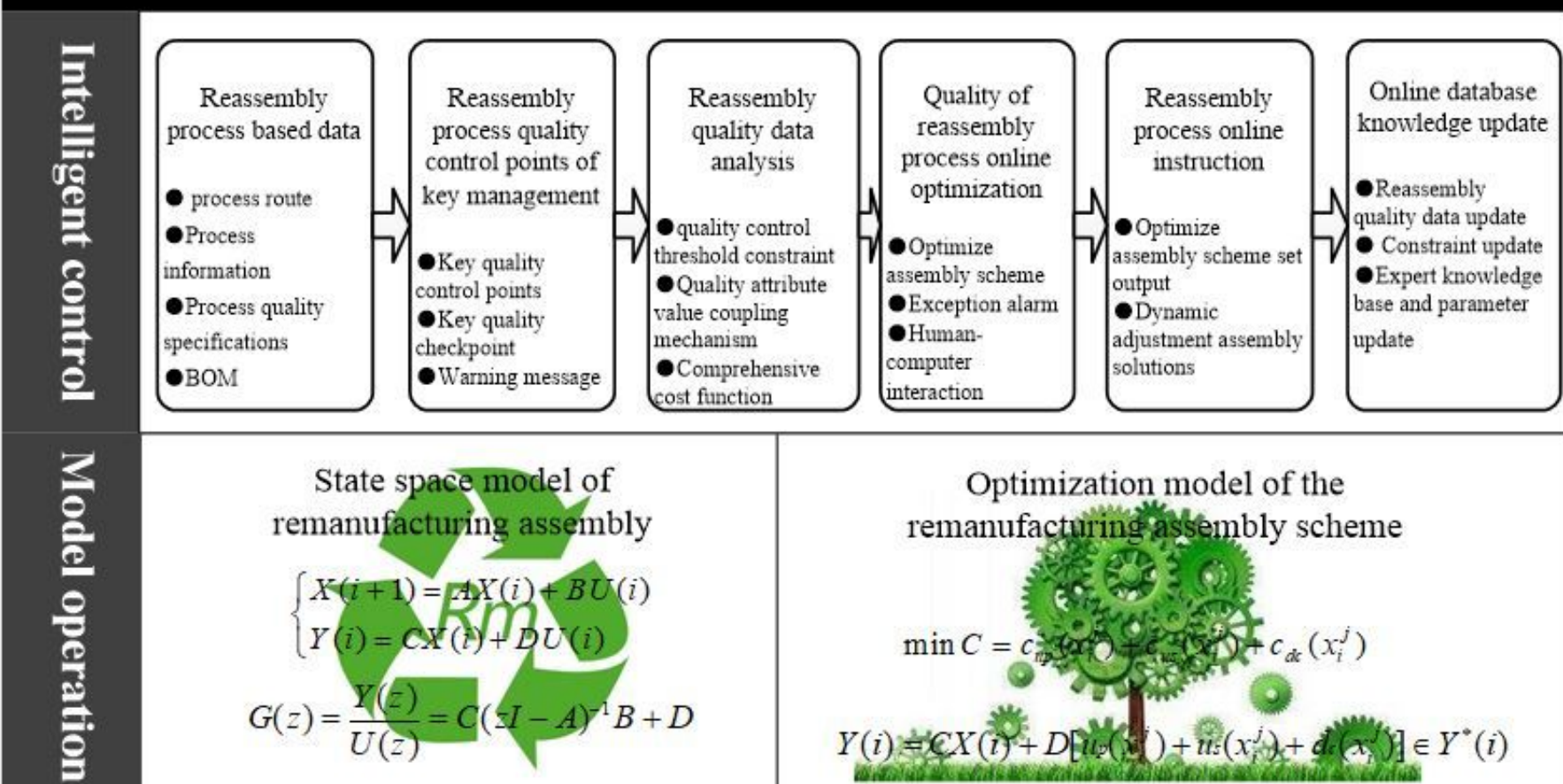

Optimization model of the remanufacturing asssembly scheme

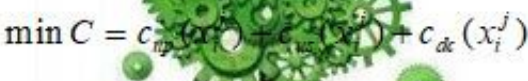

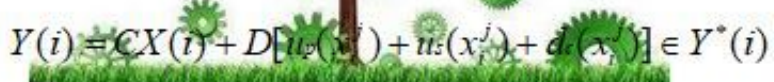

Data access (API、ADO、ADO.NET、JDBC、Generic Data Access)

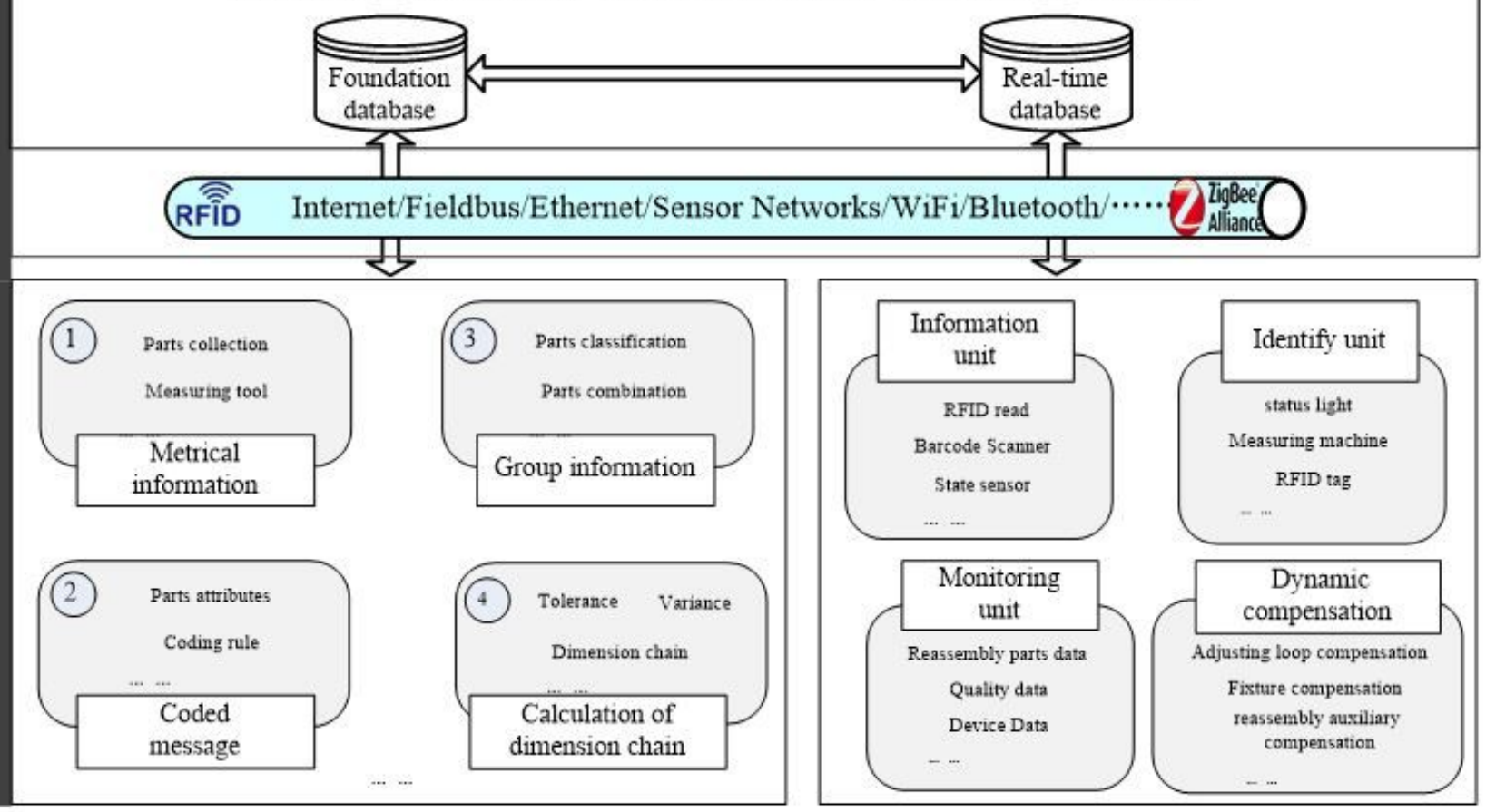

Figure 1

The framework of the intelligent control system 


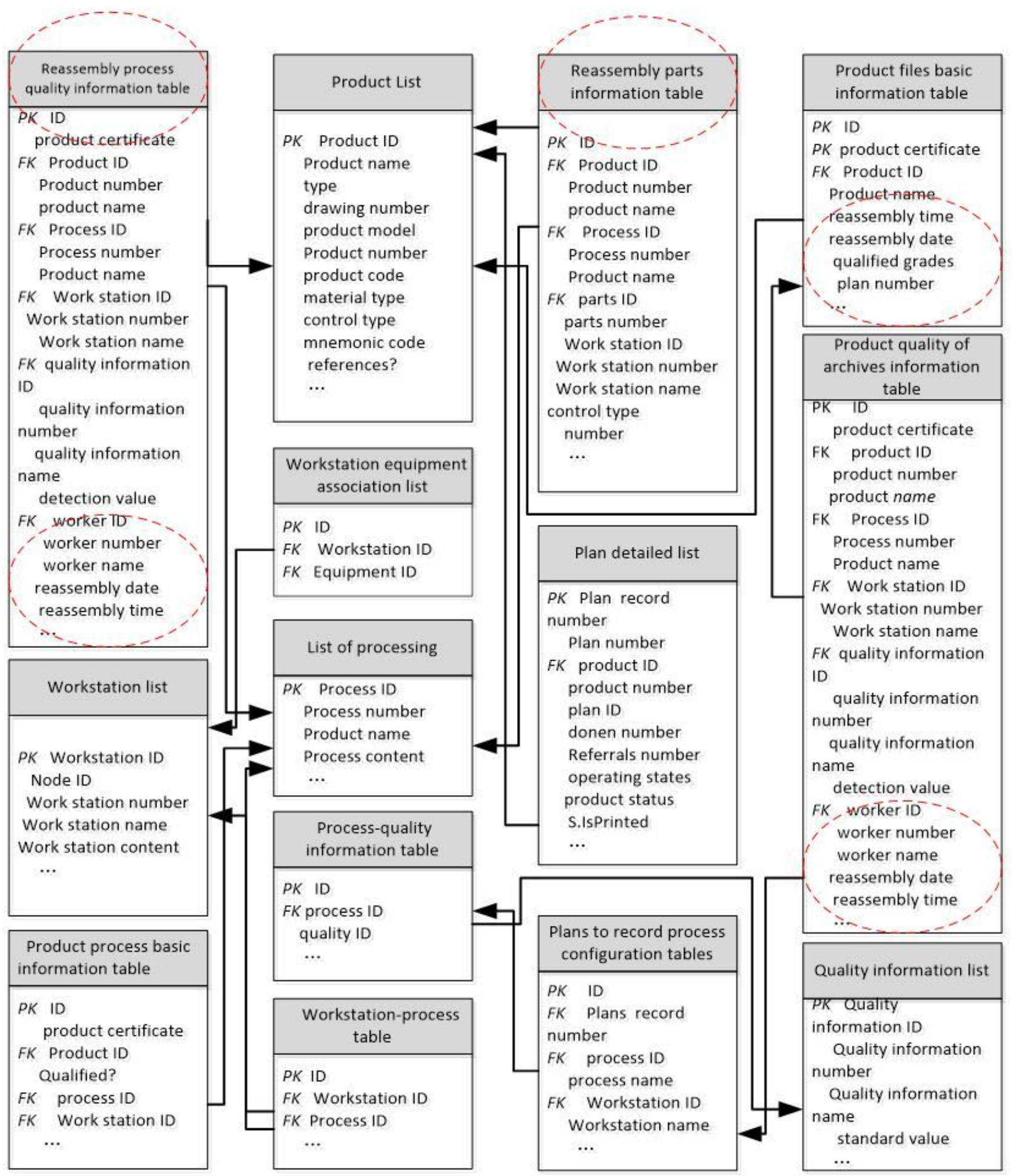

\section{Figure 2}

\section{Data model}




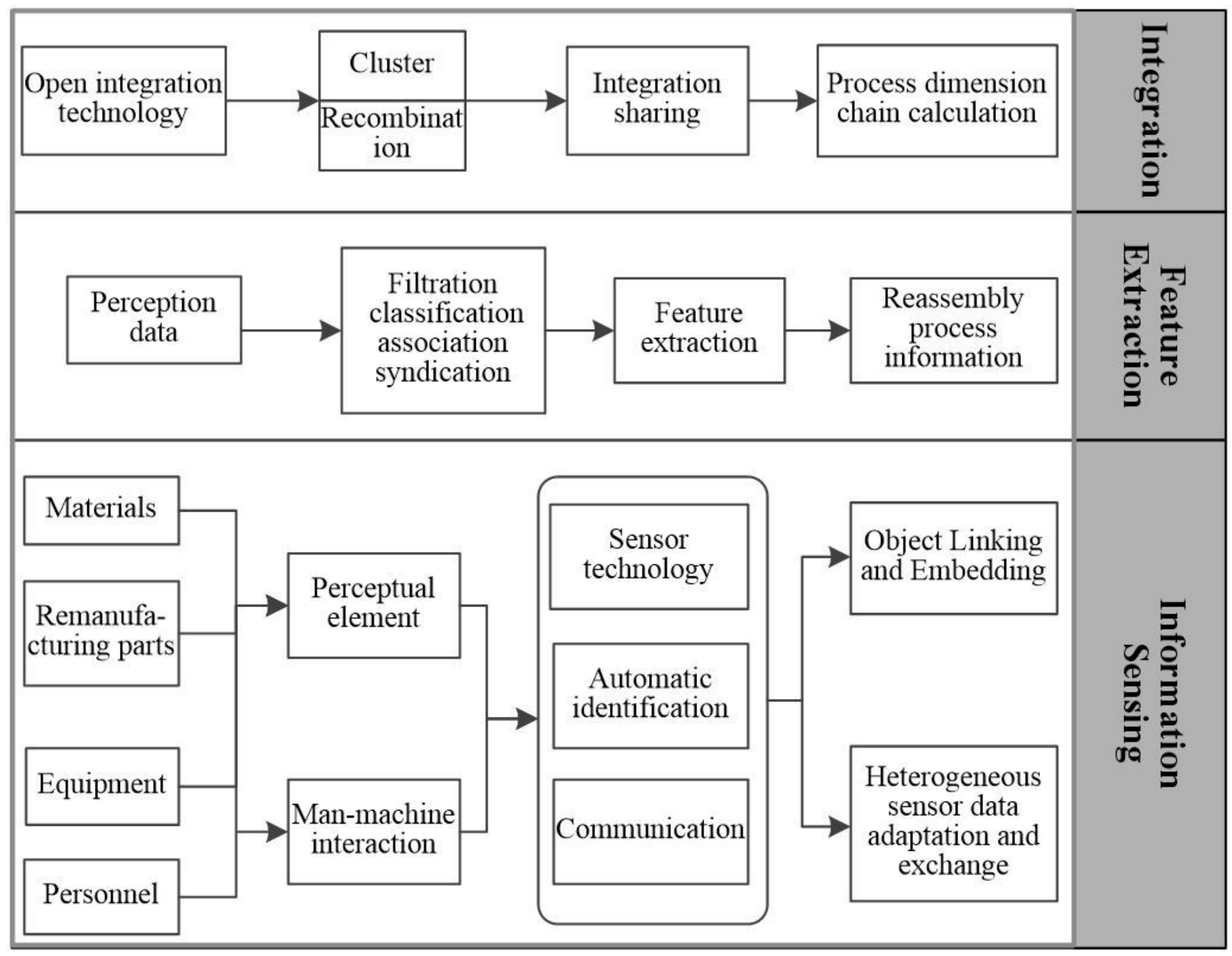

\section{Figure 3}

Information perception and fusion technology

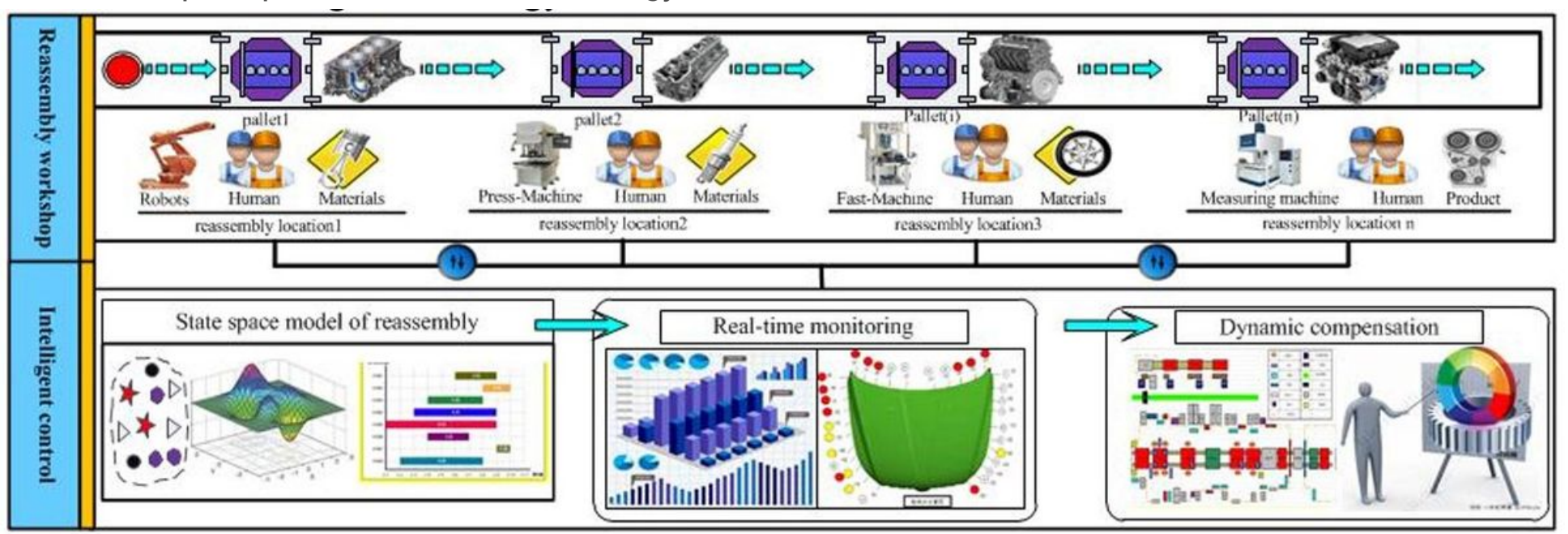

Figure 4 
Real-time monitoring and dynamic compensation of reassembly quality

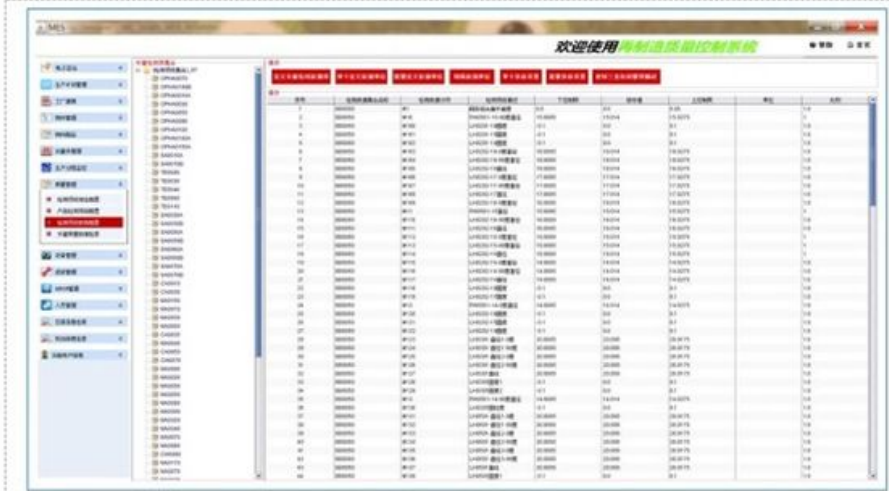

I: Information collection of remanufactured parts

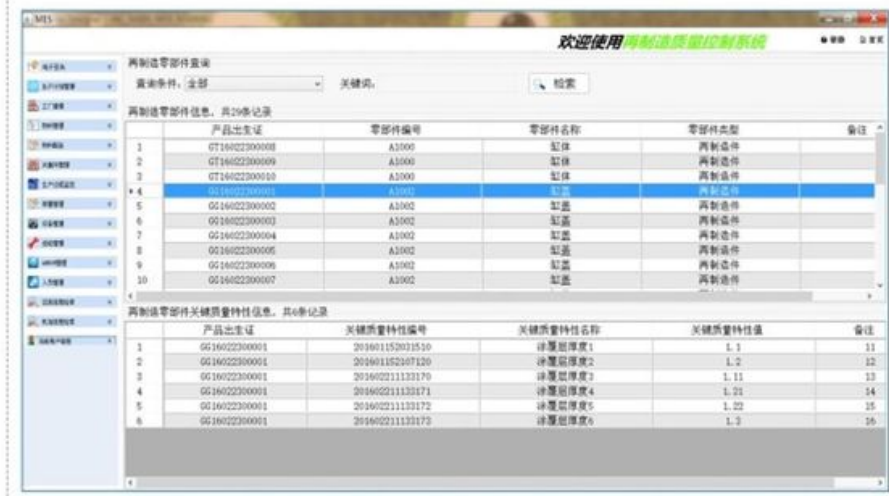

III: Key quality information retrieval of remanufactured parts

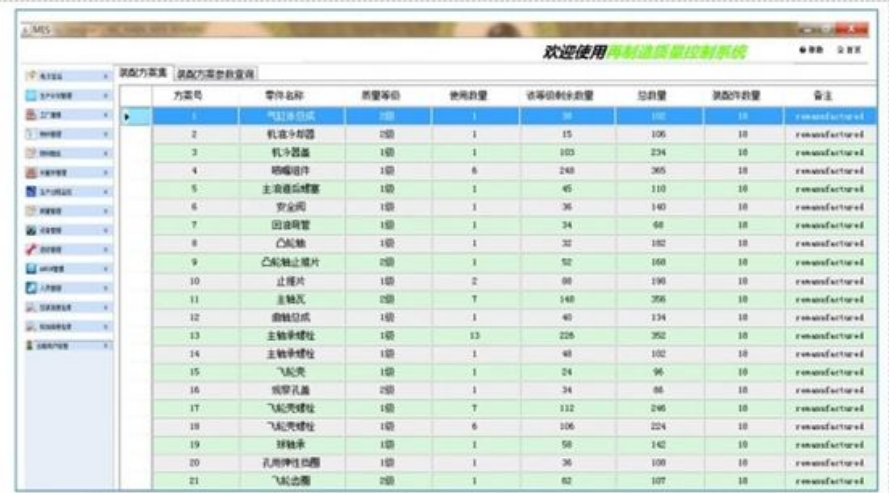

II: Inventory information of remanufactured parts

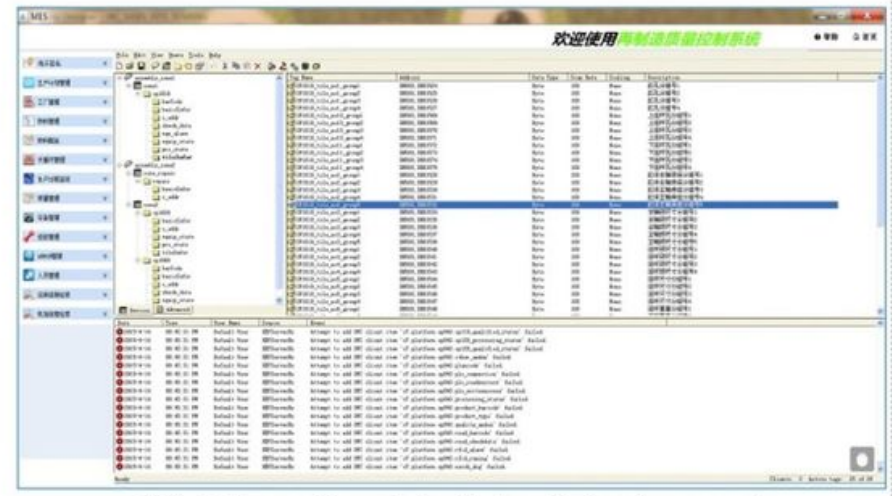

IV: Information data fusion in background

\section{Figure 5}

Information collection and fusion module of prototype intelligent control system 


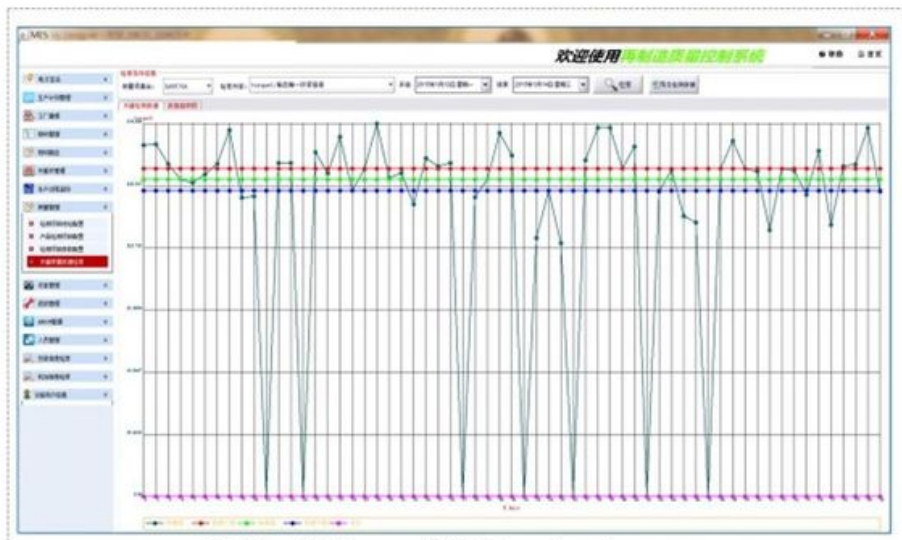

I: Prediction of tightening torque

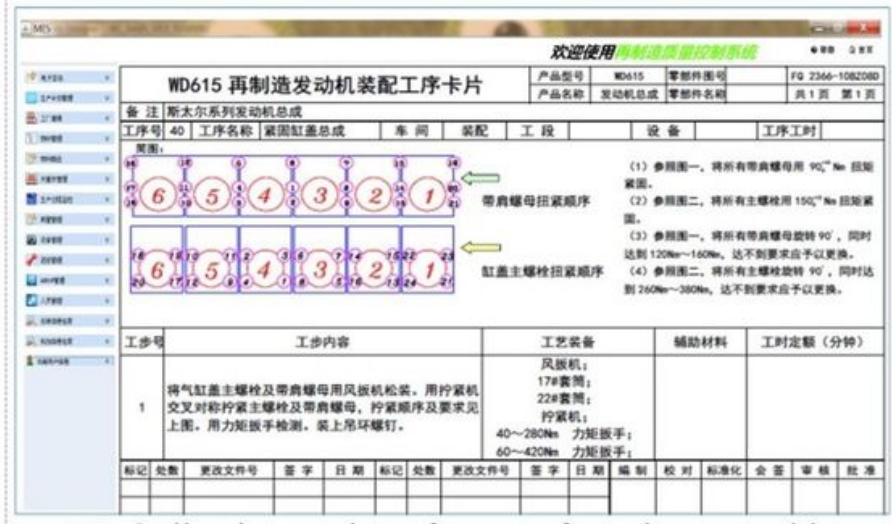

III: Online instruction of remanufacturing assembly

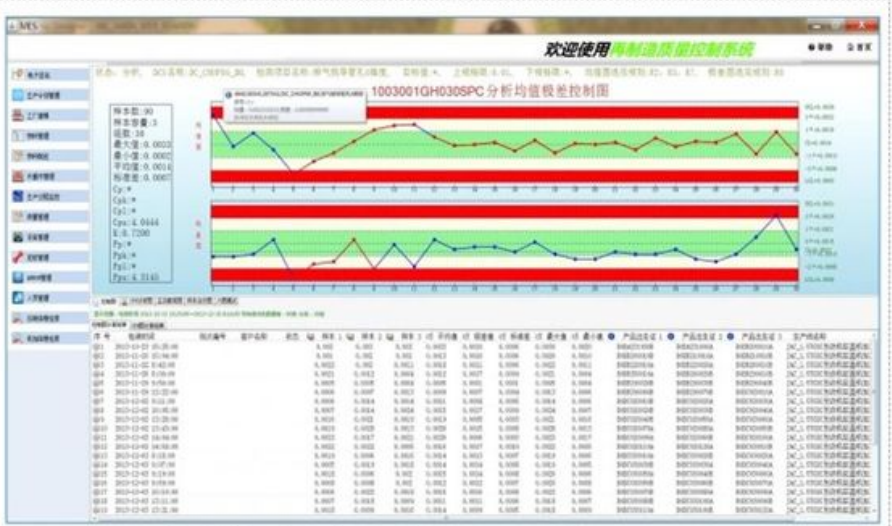

II: Monitoring of reassembly process

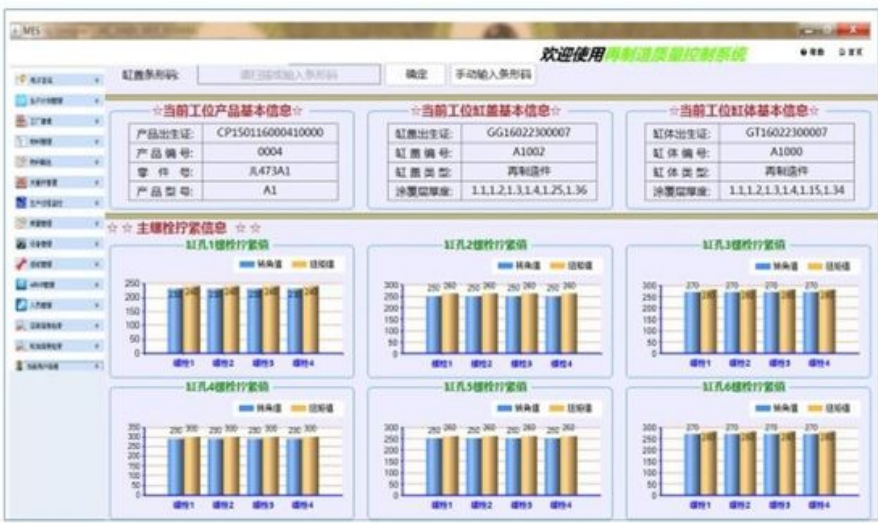

IV: Display of real time data

Figure 6

Monitoring and online guidance of prototype intelligent control system 